\title{
Worker Protection Standard: Requirements for Agricultural Employers of Workers and Handlers ${ }^{1}$
}

\author{
Frederick M. Fishel ${ }^{2}$
}

\section{Background}

In 1992, the US Environmental Protection Agency (EPA) issued a comprehensive regulation called the Worker Protection Standard for Agricultural Pesticides (WPS). This regulation is primarily intended to reduce the risks of illness or injury to workers and handlers resulting from occupational exposures to pesticides used in the production of agricultural plants on agricultural establishments (i.e., farms, forests, nurseries, and enclosed space production facilities, such as greenhouses). The WPS requires agricultural employers to take steps to reduce pesticide-related risks when agricultural workers and pesticide handlers are exposed to these pesticides. The EPA has made several changes to the WPS since it was fully implemented in 1995. On November 2, 2015, the EPA revised the WPS, making significant changes to the rule's requirements. Most of the revised provisions became effective January 2, 2017; there are four provisions that are delayed until January 2, 2018. In late 2016, the EPA released the revised "How to Comply Manual" to provide an updated resource. The entire document is posted on their website at https://www.epa.gov/ sites/production/files/2016-09/documents/htcmanual_final. pdf. This document will address the requirements for agricultural employers of workers and handlers under the revised WPS.

Most of the topics covered in this document apply to agricultural employers of workers and handlers. Some WPS protections employers must provide are nearly the same whether their employees are workers or handlers. The topics addressed in this document include:

- General responsibilities of agricultural employers

- Responsibilities of agricultural employers to provide instructions to supervisors

- Recordkeeping: pesticide application and hazard information

- Requests for records of pesticide application and hazard information

- Emergency assistance

- Decontamination supplies for workers and handlers

- Establishment-specific information

- Employer information exchange

- Retaliation against employees

- Employer responsibilities for WPS violations

Other topics that are relevant to agricultural employers of workers and handlers, including the requirement that agricultural employers display information at a central location and provide pesticide safety training, are discussed in separate documents.

1. This document is SS-AGR-416, one of a series of the Agronomy Department, UF/IFAS Extension. Original publication date January 2018. Visit the EDIS website at http://edis.ifas.ufl.edu.

2. Frederick M. Fishel, professor, Agronomy Department, and director, Pesticide Information Office; UF/IFAS Extension, Gainesville, FL 32611.

The Institute of Food and Agricultural Sciences (IFAS) is an Equal Opportunity Institution authorized to provide research, educational information and other services only to individuals and institutions that function with non-discrimination with respect to race, creed, color, religion, age, disability, sex, sexual orientation, marital status, national origin, political opinions or affiliations. For more information on obtaining other UF/IFAS Extension publications, contact your county's UF/IFAS Extension office. 


\section{General Responsibilities of Agricultural Employers}

Agricultural employers must:

- Ensure that all pesticides at all times are used in a manner consistent with the pesticide product label, including following the WPS requirements when applicable.

- Provide each worker and handler the protections required by the WPS.

- Verify that each handler, or worker that conducts earlyentry tasks, is at least 18 years old.

- Ensure that employees do not clean, repair, or adjust pesticide-application equipment without completing WPS handler training.

- Never allow other persons (anyone not employed by the agricultural establishment) to clean, repair, or adjust pesticide application equipment until those persons are told:

- That the equipment may be contaminated with pesticides.

- That pesticide exposure can have harmful effects.

- How they are to handle the equipment to limit exposure to pesticides.

- How to wash themselves and/or their clothes to prevent or remove pesticide residues.

- Provide records or other information required by the WPS for inspection to an employee of EPA or any duly authorized representative of a federal, state, or tribal agency responsible for pesticide enforcement.

\section{Responsibilities of Agricultural Employers to Provide Instructions to Supervisors}

If an agricultural employer employs supervisors of workers or handlers or hires workers or handlers through a labor contractor, the agricultural employer must provide sufficient instructions to the supervisors and/or labor contractors to ensure that workers and handlers receive all required WPS protections. The instructions must specify which tasks the labor contractors and/or supervisors are responsible for in order to comply with the WPS.

The agricultural employer must also require labor contractors and anyone who supervises any workers or handlers to provide sufficient information and directions to each worker and handler to ensure that they can comply with the WPS provisions applicable to their duties and tasks as a worker or handler.

Agricultural employers and their supervisors must clearly understand each of the responsibilities for complying with the WPS and ensure that they are implemented. Even if the agricultural employer assigns a supervising employee or labor contractor to carry out the duties required by the WPS, the agricultural employer is ultimately responsible for making sure that all those duties are performed.

\section{Recordkeeping: Pesticide Application and Hazard Information}

If the pesticide application and hazard information for either general-use or restricted-use pesticides is required to be displayed, the agricultural employer must keep a record of the application and hazard information on the establishment for 2 years from the expiration date of the REI (Restricted Entry Interval) of the pesticide applied. Pesticide records must contain:

- Name of the pesticide applied,

- Active ingredient,

- EPA registration number,

- REI,

- Crop or site treated,

- Location and description of the treated area(s),

- Date(s) and times application started and ended, and

- Safety Data Sheet of the pesticide applied.

\section{Requests for Records of Pesticide Application and Hazard Information}

The pesticide application and hazard information that must be provided is limited to the 2-year record-retention requirement. Information must be provided within 15 days of the request.

Workers and handlers may request a copy of, or access to, the pesticide application information and hazard information if:

- The person is, or was employed as a worker or handler by the establishment during the period when the information was to be displayed and maintained, and 
- The request is made orally or in writing.

Medical personnel treating agricultural workers and handlers, and any person acting under the supervision of such medical personnel, may request access to, or a copy of, pesticide application and hazard information for the diagnosis or treatment of a worker or handler who was employed on the agricultural establishment during the period that the information was required to be displayed. This request can be made orally or in writing. The information must be provided promptly after receiving the request.

A designated representative of a worker or handler may request access to, or a copy of, pesticide application and/or hazard information. The request must be made in writing and contain the following information:

- The name of the worker or handler being represented.

- A description of the specific information being requested, including:

- Dates of employment of the worker or handler,

- The date(s) for which the records are requested,

- Type of work conducted by the worker or handler during the period for which the records are requested, and

- The specific application and hazard information requested.

- A written statement clearly designating the representative to obtain this information on the worker's or handler's behalf, with the worker's or handler's printed name and signature, the date of the designation, and the printed name and contact information for the designated representative.

- An address, if the information is to be sent.

Upon receiving a written request from a designated representative complete with the required information, the agricultural employer must provide a copy of, or access to, the requested information within 15 days.

If a record has been previously provided without cost to a worker or handler or their designated representative, a reasonable fee may be charged for duplicate records, but the fee may not include any non-discriminatory costs (no overhead charges).

\section{Emergency Assistance}

Agricultural employers must provide transportation and emergency information promptly for their workers and handlers after learning of the possible poisoning or injury if:
- There is reason to believe that a worker or handler experienced a potential pesticide exposure during his or her employment on their employer's agricultural establishment, or

- Workers or handlers show symptoms similar to those associated with acute exposure to pesticides during or within 72 hours after employment on the agricultural establishment and need emergency medical treatment.

Agricultural employers must make emergency transportation available to take injured persons from the agricultural establishment (including from any worker housing on the establishment) to a medical care facility capable of providing emergency medical treatment to a person exposed to pesticides. Employers can "make transportation available" by:

- Taking the employee to the medical care facility, or

- Calling an emergency vehicle, such as an ambulance, or

- Making sure the employee has a ride to the medical care facility with someone else.

Provide all of the following emergency information to the treating medical personnel:

- Copies of the applicable SDS, the pesticide product name, EPA registration number, and active ingredient(s) for each pesticide product to which the person may have been exposed.

- Type of application (or how the pesticide was used) on the agricultural establishment.

- The circumstances that could have resulted in exposure to the pesticide.

\section{Decontamination Supplies for Workers and Handlers}

To prevent or mitigate pesticide exposures, agricultural employers are required to provide equipment and supplies for routine washing to remove pesticide residues, emergency decontamination, and, in certain situations, immediate eye flushing to all workers and handlers, including early-entry workers.

\section{Establishment-Specific Information}

All agricultural employers must provide information specific to their agricultural establishments to workers and handlers when they first enter the establishment and before they begin WPS tasks in areas where, within the last 30 
days, a WPS-labeled pesticide product has been applied or a REI for such pesticide has been in effect.

The agricultural employer must inform workers and handlers in a manner they understand about the location of the following on the establishment:

- Pesticide safety information,

- Pesticide application and hazard information, and

- Decontamination supplies.

Establishment-specific information must be provided even if the worker or handler has already received the annual pesticide safety training on another agricultural establishment and verification of such training is provided to the agricultural employer. Recordkeeping is not required for providing this information. For example, if a worker/ handler is WPS-trained at farm A and later in the summer starts to work for farm B (and the agricultural employer of farm B obtains the worker's/ handler's training records), the farm B agricultural employer only needs to provide the worker/handler with the establishment-specific information.

Providing establishment-specific information is not a requirement for commercial pesticide handler employers.

\section{Employer Information Exchange}

Whenever a handler, including crop advisors, of a commercial pesticide handler employer (CPHE) conducts pesticide-handling tasks on an agricultural establishment, the agricultural employer must provide the CPHE with specific information about treated areas on the establishment they will be working on.

Conversely, the CPHE (employer of the for-hire/custom applicators or crop advisors) must provide the agricultural employer, as their customer and the operator of the agricultural establishment, with certain information about a pesticide product before applying it on the establishment. This exchange of information can be accomplished through electronic media, telephone, or other means.

The operator of an agricultural establishment must inform the hired CPHE of the following:

- The specific location and description of any treated areas on the agricultural establishment under a REI that the handler may be in (or walk within 1/4 mile of), and

- Any restrictions on entering those areas.
All CPHEs must inform their handlers of the information provided by the agricultural employer.

To allow an agricultural employer to inform workers on the establishment about a pesticide application that is, or will be performed, the CPHE must inform the agricultural employer of the following:

- Specific location and description of the area(s) on the agricultural establishment that are to be treated with a pesticide,

- Date and start and estimated end times of the application,

- Pesticide product name, EPA registration number, and active ingredient(s),

- REI for the pesticide product,

- Whether the pesticide product labeling requires posting, oral notification, or both, and

- Any other specific requirements on the pesticide product labeling about protection of workers and other persons during or after application.

The CPHE must provide the agricultural employer with updated information before the application when there are any changes to:

- The location to be treated,

- REI,

- Method of notification,

- Labeling requirements to protect workers/other persons, or

- The start time, if it will be earlier than estimated.

If the pesticide product information changes, or if there are other changes to the date or the start and end time, the CPHE must provide the updated information to the agricultural employer within 2 hours after completing the application. Changes to the estimated application end time of less than one hour do not need to be reported to the agricultural employer.

\section{Retaliation Against Employees}

The agricultural employer, their supervisors, or others cannot intimidate, threaten, coerce, discriminate against, discourage, or fire any worker or handler or in any way seek to prevent a worker or handler from complying or attempting to comply with the WPS. Additionally, the agricultural employer cannot retaliate in any manner if any worker or handler: 
- Refuses to participate in any activity that the worker or handler reasonably believes to be in violation of the WPS,

- Has reported or is about to report WPS noncompliance to appropriate authorities for enforcement of WPS provisions,

- Agrees to provide information to the EPA or any duly authorized representative of a federal, state, or tribal government about WPS compliance, or

- Assists or participates in any manner in an investigation, proceeding, or hearing concerning WPS compliance.

For example: if the employer or supervisor refuses to provide PPE or tells an early-entry worker to enter a treated field during the REI without providing specific information and PPE and the employee files a complaint to authorities, the employer may not fire or threaten that person in any manner or allow any acts of retaliation by any employee.

\section{Employer Responsibilities for WPS Violations}

Agricultural employers of workers and handlers can be subject to civil and criminal penalties if they do not comply with the federal WPS, including all revisions to this rule. Failure to comply is a pesticide-misuse violation because the WPS is referenced on applicable pesticide product labeling. Failure to comply with distinct requirements of the WPS can result in independently assessable charges, even if the violative acts occurred during one pesticide application.

The Federal Insecticide, Fungicide and Rodenticide Act (FIFRA) includes provisions that hold owners and agricultural employers liable for a WPS penalty if another person employed by or acting for them, including labor contractors, farm managers, and/or other supervisors, fails to comply with any WPS requirements. The term "acting for" includes both employment and contractual relationships.

\section{Additional Information}

Frederick M. Fishel. 2015. A Summary of Revisions to the Worker Protection Standard - 2015. PI261. Gainesville: University of Florida Institute of Food and Agricultural Sciences. http://edis.ifas.ufl.edu/pi261.

Frederick M. Fishel and Tatiana Sanchez. 2016. Worker Protection Standard: Information at a Central Location. PI112. Gainesville: University of Florida Institute of Food and Agricultural Sciences. https://edis.ifas.ufl.edu/pi149.

Frederick M. Fishel. 2016. Worker Protection Standard: Training Workers and Handlers under the 2016 Revision
Requirements. PI268. Gainesville: University of Florida Institute of Food and Agricultural Sciences. https://edis.ifas. ufl.edu/pi268.

US EPA. 2016. "How to Comply with the 2015 Revised Worker Protection Standard for Agricultural Pesticides: What Owners and Employers Need to Know". EPA 735-B16-001. United States Environmental Protection Agency. https://www.epa.gov/sites/production/files/2016-09/documents/htcmanual_final.pdf. 